\title{
İnsansız Hava Araçları Kullanılarak Olası Kaya Düşmelerinin Coğrafi Bilgi Sistemleri Tabanlı 3D Modellenmesi: Kasımlar Köyü (Isparta-Türkiye) Örneği
}

\author{
Erhan ŞENER ${ }^{* 1}$
}

1Süleyman Demirel Üniversitesi, Uzaktan Algılama Araştırma ve Uygulama Merkezi, 32260, Isparta, TÜRKIYE

(Alınış / Received: 24.12.2018, Kabul / Accepted: 30.05.2019, Online Yayınlanma / Published Online: 30.08.2019)

\author{
Anahtar Kelimeler \\ İnsansız hava araçları, \\ Fotogrametri, \\ Ortofoto, \\ Nokta bulutu, \\ Coğrafi bilgi sistemleri, \\ Kaya düşmelerinin 3D modellenmesi
}

\begin{abstract}
Özet: Kaya düşmeleri jeolojik tabanlı doğal afetlerden birisi olup litoloji, süreksizlikler, eğim, ayrışma, pürüzlülük, bitki örtüsü gibi faktörlerin kontrolünde gelişmektedir. Mühendislik projelerinde kaya düşmelerinin modellenmesine yönelik genel olarak 2 ve 3 boyutlu çözümler bulunmakla birlikte 3D çözümler doğal ortamı daha hassas modellemesinden dolayı son yıllarda çok sık kullanılmaya başlanmıştır. İnsansız hava araçlarının gelişerek kullanımlarının yaygınlaşmasıyla birlikte yüksek çözünürlüklü ortofotolar ile nokta bulutu oluşturularak topografya ve bitki örtüsünün yanısıra ulaşımı çok zor olan dik yamaçlardaki süreksizliklerin konumları ile blok boyutları hakkında çok değerli veriler toplanabilmektedir. Bu çalışmada, İnsansız Hava Aracı kullanılarak fotogrametrik yöntemler ile Isparta İli, Sütçüler İlçesi Kasımlar Köyündeki potansiyel kaya düşmeleri Coğrafi Bilgi Sistemleri ortamında 3D olarak modellenmiştir. Aynı zamanda olası kaya düşmelerindeki düşen blokların yörüngeleri, düşme açıları, sıçrama yükseklikleri ve enerjileri hesaplanarak risk altında bulunan alanlar haritalandırılmıştır. Boyutları yaklaşık $26 \mathrm{~m}^{3}$ ile $355 \mathrm{~m}^{3}$ arasında değişen 4 adet blok için yapılan 3D modelleme sonuçlarına göre olası kaya düşmelerindeki maksimum kinetik enerjilerin $55170 \mathrm{~kJ}$, maksimum sıçrama yüksekliklerinin $11.5 \mathrm{~m}$ ve maksimum düşme hızlarının ise $24.7 \mathrm{~m} / \mathrm{s}$ olduğu belirlenmiştir.
\end{abstract}

\section{D Modeling of Possible Rockfall Using Unmanned Aerial Vehicles Based on Geographic Information System: The Case of the Kasımlar Village (Isparta, Turkey)}

\section{Keywords}

Unmanned aerial vehicles, Photogrammetry,

Orthophoto,

Point cloud,

Geographic information systems,

3D modeling of rock falls

\begin{abstract}
Rockfalls are one of the geological-based natural disasters and it develops in the control of factors such as lithology, discontinuities, slope, decomposition, roughness and vegetation. There are generally 2 and 3 dimensional solutions for the modeling of rock falls in engineering projects. However, 3D solutions have been used frequently in recent years because they simulate the natural environment more precisely. With the widespread use of unmanned aerial vehicles, very valuable data can be collected about the location and block size of discontinuities on steep slopes, which are very difficult to access as well as topography and vegetation creating a point cloud with orthophotos. In this study, potential rock drops in Kasımlar Village of Sütçüler District in Isparta Province were modeled as 3D in Geographic Information Systems with photogrammetric methods using Unmanned Aerial Vehicle. At the same time, the trajectories of falling blocks belongs to possible rockfalls, trajectory, passing heights and energies are calculated and areas under risk are mapped. According to the results of 3D modeling for four blocks ranging in size from $26 \mathrm{~m}^{3}$ to $355 \mathrm{~m}^{3}$, the maximum kinetic energy is $55170 \mathrm{~kJ}$, the maximum passing heightis $11.5 \mathrm{~m}$ and the maximum simulated velocity are $24.7 \mathrm{~m} / \mathrm{s}$. .
\end{abstract}




\section{Giriş}

Kaya düşmeleri, dik topoğrafyaya sahip alanların yüksek kotlarında yüzeylenen eklemli kaya ortamlarında, süreksizliklerin sınırlandırdığı kaya bloklarının serbest yüzeye doğru küçük hareketlerde duraylılığını yitirerek, kaynak bölgeden eğim aşağı oldukça hızlı olarak hareket ettiği bir tür yamaç duraysızlığıdır [1-4]. Düşen blokların boyutları parke taşlarından yüzlerce $\mathrm{m}^{3}$ boyutunda olabilir [5]. Yüksek hızları ve enerjileri nedeniyle, kaya düşmeleri önemli ölçüde maddi hasar ve yaşam kaybına neden olabilmektedir. Kaya düşmeleri genel olarak jeolojik koşullar tarafından kontrol edilir. Formasyonların litolojik özellikleri, iklimsel parametrelerin ayrışma sürecine etkileri ile kayaçlardaki süreksizliklerin konumu düşen blokların boyutları ile şekillerinde önemli rol oynar [6]. Bunun yanı sıra donma çözülme döngülerinin etkisi ile şiddetli yağışlarda kaya düşmelerinin önemli nedenlerindendir [7-9].

Ülkemizde başta Karadeniz Bölgesi olmak üzere birçok bölgede kaya düşmeleri çok sık yaşanmaktadır. Ülkemizde yerleşim bölgelerini etkileyerek resmi kayıtlara geçen 2956 adet kaya düşmesi olayı ve kaya düşmelerinden etkilenen 19422 afetzede bulunmaktadır. En fazla kaya düşmesinin yaşandığı ilimiz 279 adet ile Kayseri olup sırasıyla Erzurum (229), Nevşehir (179), Adıyaman (135) ve Sivas (129) kaya düşmesi olaylarının en çok yaşandığı diğer illerimizdir (Şekil 1)[10].

Kaya düşmelerinin etkilerinin en aza indirilebilmesi için öncelikle riskli bölgelerde 2 ve/veya 3 boyutlu modelleme çalışmaları yapılarak düşmesi muhtemel blokların düşme yörüngeleri, sıçrama yükseklikleri, kinetik enerjileri vb. parametreler belirlenmelidir. Sözkonusu parametrelerin sayısal değerlerine göre olası kaya düşmelerin önlenmesi ve/veya etkilerinin en aza indirilmesi amacıyla bariyer, hendek, çelik tel ağ sistemleri, çivileme, yerinde kırma vb. önleme çalışmalarından en uygun olanı belirlenebilir. $\mathrm{Bu}$ çalışmada, Isparta İli, Sütçüler İlçesi Kasımlar Köyündeki olası kaya düşmeleri İnsansız Hava Aracı kullanılarak fotogrametrik yöntemler ile Coğrafi Bilgi Sitemleri ortamında 3 boyutlu olarak modellenmiștir. Aynı zamanda olası kaya düşmelerinde blokların düşme yörüngeleri, sıçrama yükseklikleri ve enerjileri hesaplanarak risk altında bulunan alanlar haritalandırılmıștır.

\section{Materyal ve Yöntem}

Çalışma alanı Isparta ilinin güneyinde yeralan Sütçüler ilçesine bağlı Kasımlar köyüdür. Sütçüler ilçe merkezinin yaklaşık $45 \mathrm{~km}$ doğusunda yeralan Kasımlar köyü, Yukarı Köprüçay havzasında yoğun engebeli bir arazide bulunmaktadır (Şekil 1). Özellikle son yıllarda verdiği göçler nedeniyle nüfusu önemli oranlarda azalan Kasımlar Köyünün Adrese Dayalı Nüfus Kayıt Sistemi (ADNK) verilerine göre 2017 yılı nüfusu 457'tür. Kasımlar Köyünde önceki yıllarda birçok defa kaya düşmesi yaşanmış olup sözkonusu düşen blokları köy içerisinde özellikle yamaç çevresindeki evlerin etkilerinin etrafında görmek mümkündür.

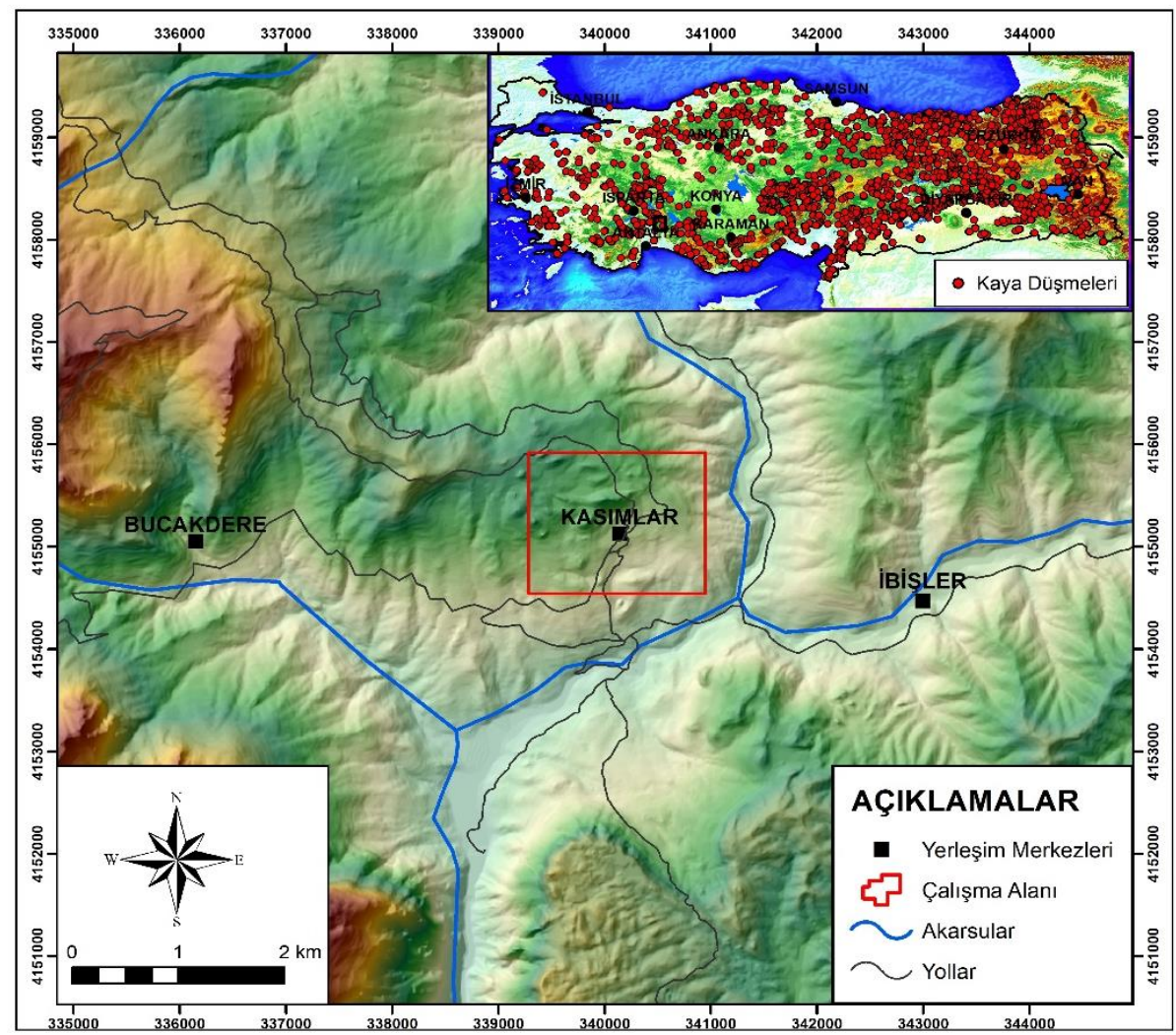

Şekil 1. Çalışma alanının yerbulduru haritası 
Bu çalışmada öncelikle DJI Matrice 600 Pro insansız hava aracı kullanılarak Sony A7R kamera ile çalışma alanına ait 752 adet hava fotoğrafı çekilmiștir. Sözkonusu hava fotoğrafları Pix4D Mapper yazılımı ile fotogrametrik olarak değerlendirilerek çalışma alanının yüksek çözünürlüklü ortofoto haritası ile nokta bulutu oluşturulmuştur.

Kaya düşmelerinin modellenmesine yönelik 2 boyutlu istastiksel modellerden ve 3 boyutlu deterministik modellere kadar değișen modelleme teknikleri mevcuttur. [11, 12]. Özelikle son yıllarda sayısal haritalama ve mekansal modelleme tekniklerinin gelişimi ile yerel ve bölgesel ölçekte 3 boyutlu hibrit deterministik-olasılıksal kaya düşmesine yönelik simülasyon modelleri yoğun olarak kullanılmaktadır [11, 13-15].

Rockyfor3D kaya düşmelerinde düşen blokların yörüngesini 3 boyutlu olarak hesaplayan bir simülasyon modelidir. $\mathrm{Bu}$ model stokastik yaklaşımlarla deterministik algoritmaların kombinasyonundan oluşmaktadır. Olasılıklı süreç tabanlı kaya düşmesi yörünge modeli' olarak da adlandırılan Rockyfor3D bölgesel ve yerel ölçekli kaya düşmesi simülasyonlarında yoğun olarak kullanılmaktadır [16]. Rockyfor3D yazılımı Fransız Alplerindeki ormanlık ve ormanlık olmayan alanlarda yaşanan 218 gerçek boyutlu kaya düşmesi deneyinden elde edilen verilerle geliştirilmiştir [14, 15]. Modelde düşen blokların geri tepmeleri sonrası blok hızlarının hesaplanmasında en önemli parametrelerden bir tanesi teğetsel restitüsyon katsayıdır. Restitüsyon katsayısı yüzey pürüzlülügü ile blok boyutları ile belirlenir (Şekil 2)[12]. Denklem 1 ile ifade edilir [17].

$$
R t=\frac{1}{1+\left(\frac{M O H+D p}{R}\right)}
$$

Burada; Rt, Restitüsyon katsayısı (Geri tepme katsayısı), MOH, Yüzey pürüzlülügünden kaynaklanan ortalama engel yüksekliği, Dp, penetrasyon derinliği ve $\mathrm{R}$, düşen bloğun yarıçapını ifade etmektedir.

Elde edilen Restitüsyon katsayısı geri tepmeden sonra teğetsel hız bileşeninin $\left(\mathrm{Vt}_{2}\right)$ hesaplanması için kullanılır.

$$
V t_{2}=\frac{\sqrt{R^{2} *\left(I * V_{\text {rot } 1}^{2}+\text { RockMass } * V_{t 1}^{2}\right) * R t}}{I+\text { RockMass } * R^{2}}
$$

Burada $\mathrm{Vt}_{2}$, geri tepmeden sonraki teğetsel hız bileşeni, $\mathrm{Vt}_{1}$, bloğun geri tepmeden sonraki teğetsel

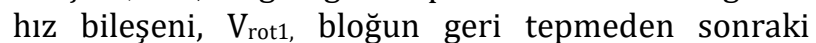
rotasyonel hız bileşeni, I, tanımlanan bloğun momenti ve RockMass, kayaç kütlesi (kg) değerini ifade etmektedir.

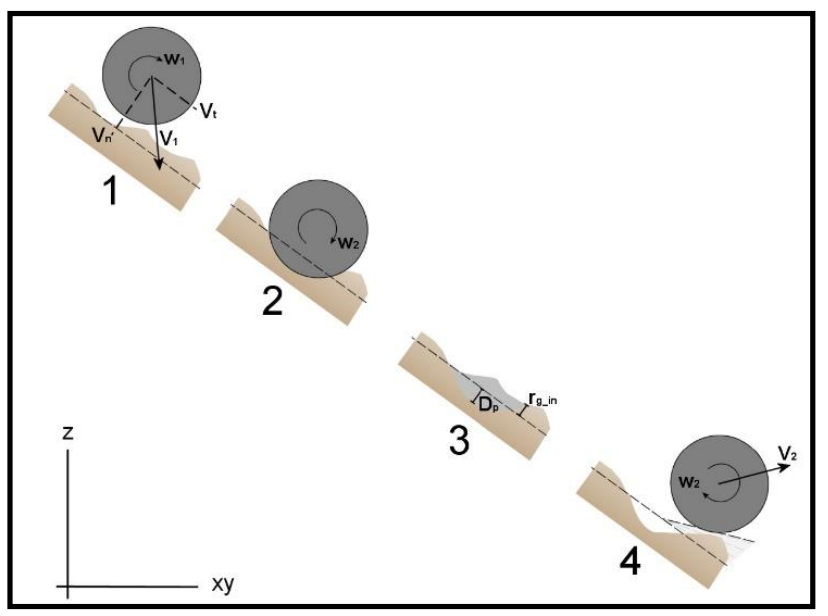

Şekil 2. $\quad$ Rockyfor3D modelinde kullanılan blok hareketlerinin șematik gösterimi [16].

\section{Araştırma Bulguları}

\subsection{Jeoloji}

Çalışma alanında farklı yaş ve litolojiye sahip stratigrafik birimler yüzeylenmektedir. Bölgede ayırtlanan litolojik birimler; Menteşe Dolomiti ve Kasımlar Formasyonudur. Tüm bu birimlerin üzerinde Kuvaterner örtü birimleri olan Alüvyon ve yamaç molozu bulunmaktadır (Şekil 3). Kasımlar Formasyonu ince- orta tabakall, gri, koyu gri, siyah, sarımsı kahve ve kahve renklerde, yer yer bitümlü kiltaşı, silttaşı ve kumtaşlarından oluşur. Silt ve kiltașları yapraklanma nedeniyle zaman zaman șeyl karakteri kazanmıştır [18]. Formasyon içinde Şenel vd. [19]'ne göre yedi farklı üye ayırtlanmıştır [20].

Menteşe dolomiti dolomit ve dolomitik kireçtaşlarından oluşmakta olup altta masif, yer yer kırılgan genelde ince-orta kristalli, gri, açık gri dolomitlerle başlar. Üstte kalın tabakalı gri renkli, silik megalodon izli, yer yer dolomitik kireçtaşı ara seviyeli dolomitler, daha üstte kalın tabakalı, gri, bej, açık gri renkli, megalodonlu ve algli kireçtaşı ile dolomitik kireçtaşlarını kapsar [21].

Yamaç molozu çalışma alanını batısında ve kuzeybatısında haritalanmıştır. Birim temel kayalardan türeme kil, silt, kum, çakıl ve blok boyutundaki malzemelerin taşıyıcının enerjisinin tükendiği ve arazi eğiminin azaldığ gevşek yığışımından oluşmuştur. Birim Kuvaterner yaşlı olup alüvyon ile yanal geçiş sunar. Alüvyon genel olarak çalışma alanının kuzeydoğusunda, Köprüçayın yakın çevresindeki düzlük alanlarda gözlenmektedir. Çevredeki kaya birimlerinden türeyen birim gevșek tutturulmuș kil, silt, kum, çakıl ve blok boyutundaki tortullar ve bunların ardalanmasından meydana gelmiştir.

\section{2. İnsansız Hava Aracı ile Haritalama}

Bu çalışmada araştırma sahasında insansız hava aracı ile otonom uçuşlar gerçekleştirilerek elde edilen 
verilerden yüksek çözünürlüklü Ortofoto görüntüsü ile birlikte Sayısal Arazi Modeli (SAM) ve nokta bulutu oluşturulmuştur. Bu amaçla DJI Matrice 600 Pro insansiz hava aracina monte edilen Sony A7R dijital fotoğraf makinesi kullanılmıştır (Şekil 4).

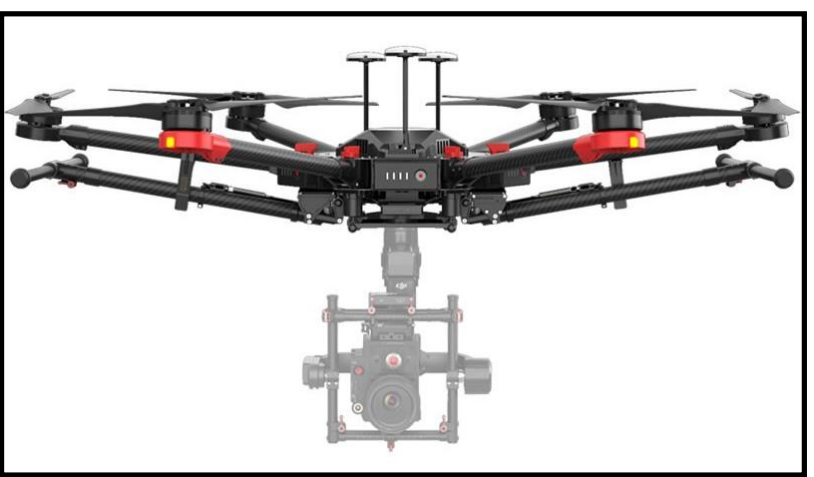

Şekil 4. Çalışmada kullanılan insansız hava aracı ile gimbal ve kamera sistemi

Sözkonusu insansız hava aracı ile Pix4D Capture yazılımı kullanılarak gerçekleştirilen otonom uçuşlar ile \%80 bindirme oranına sahip olan 752 adet hava fotoğrafı çekilmiştir. Otonom uçuşlardan elde edilen fotoğrafların istenilen projeksiyon sistemine göre yüksek doğrulukla koordinatlandırılabilmesi amacıyla çalışma alanına homojen olarak yerleştirilen yer kontrol noktaları belirlenmiştir. TUSAGA -Aktif sistemine bağlı Topcon Hyper+ GNNS alıcısı kullanılarak yer kontrol noktalarının koordinatları belirlenerek sisteme girilmiştir. İnsansız Hava aracı ile çekilen 752 hava fotoğrafının Dell $7116 \mathrm{~T}$ iş istasyonunda Pix4D yazılımı ile işlenerek çalışma alanına ait yüksek çözünürlüklü $(2,52 \mathrm{~cm} /$ pix $)$ ortofoto görüntüsü, sayısal arazi modeli ve nokta bulutu oluşturulmuştur (Şekil 5,6,7).

\subsection{Kaya Düşmelerinin 3D Modellenmesi}

Çalışma alanındaki aktif kaynak alanlarının arazi çalışmaları ve insansız hava aracı ile elde edilen veriler kullanılarak düşme potansiyeli bulunan bloklar tespit edilmiştir.

Süreksizliklerin konumları ile birlikte devamlılıkları, aralıkları ve açıklıkları vb. özellikleri kullanılarak çalışma alanında düşme potansiyeli bulunan 4 adet blok belirlenmiştir. Boyutları $26 \mathrm{~m}^{3}$ ile $355 \mathrm{~m}^{3}$ arasında değişen bu blokların hacimleri fotogrametrik yöntemler ile belirlenmiştir (Şekil 8).

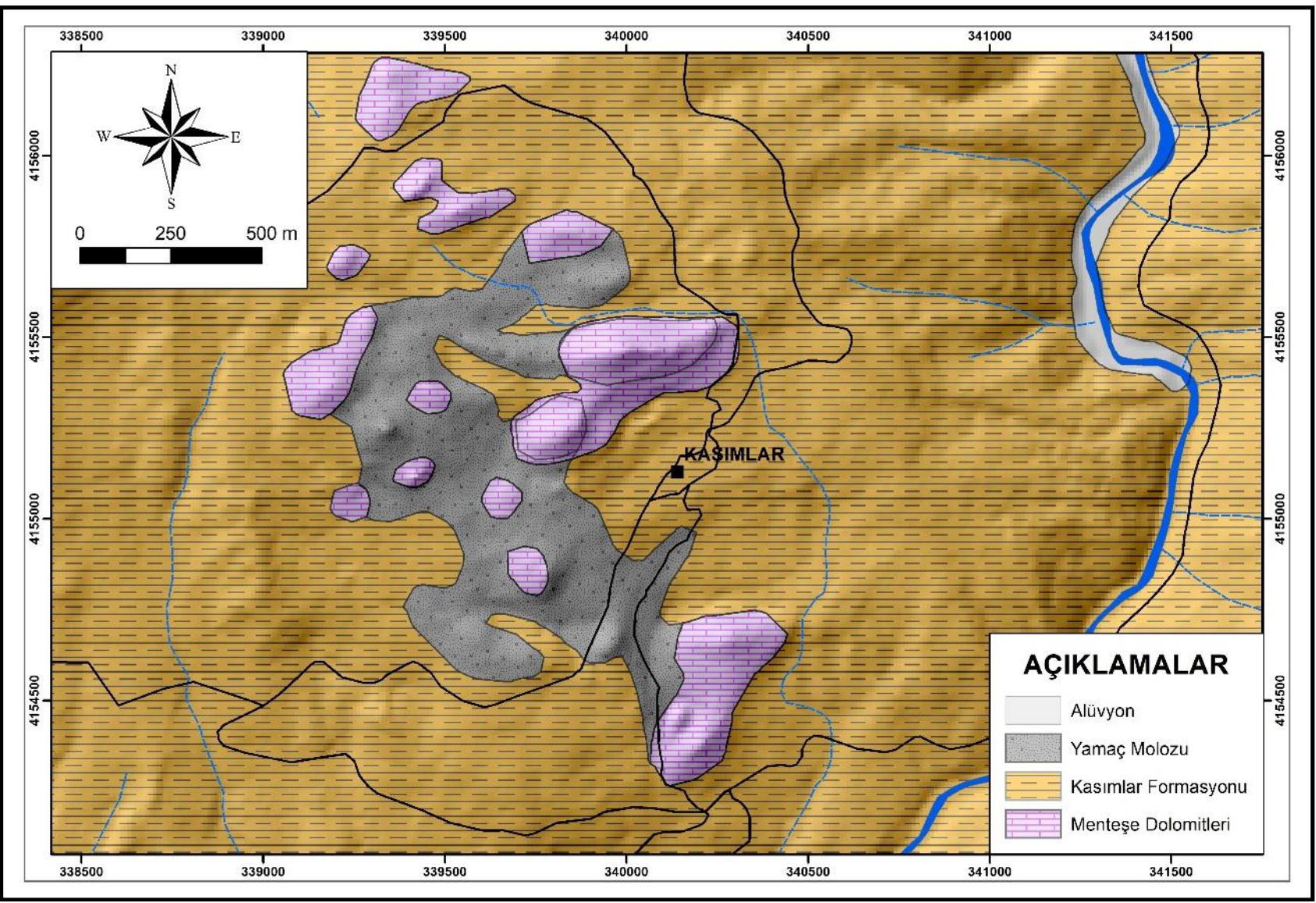

Şekil 3. Çalışma ve çevresinin jeoloji haritası 


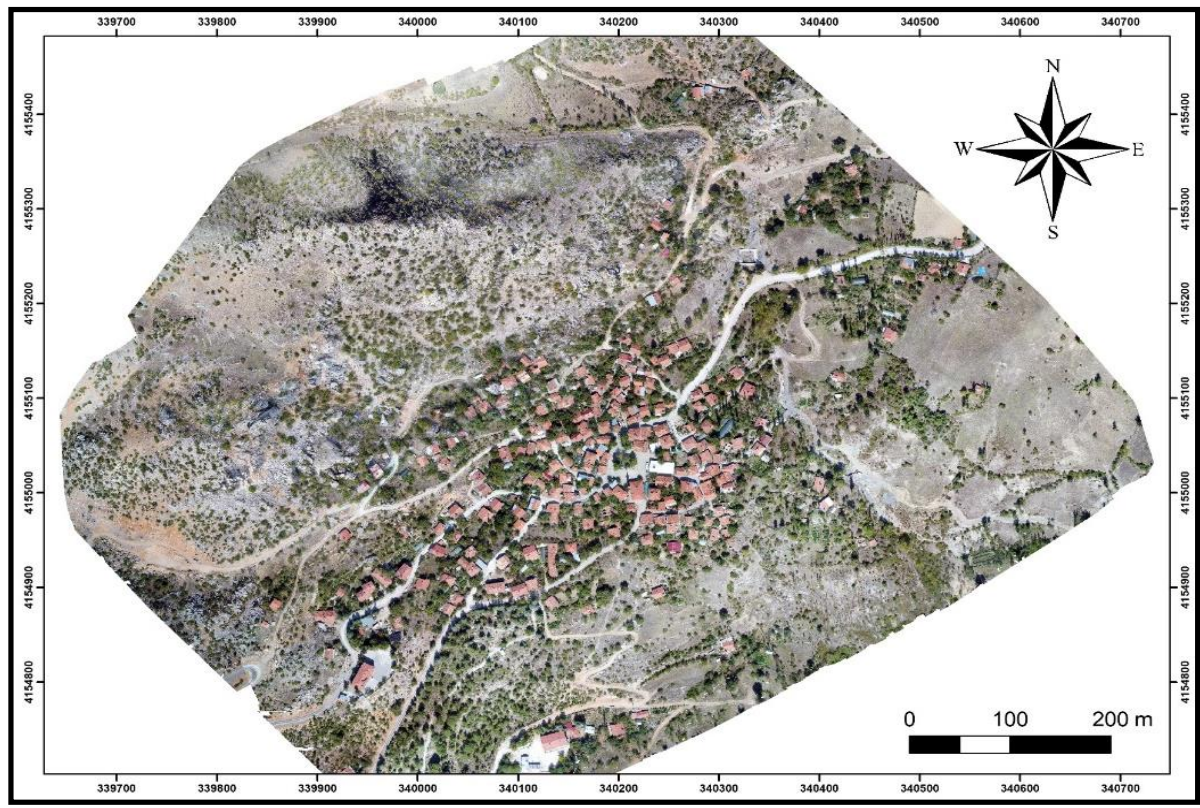

Şekil 5. Çalışma alanının yüksek çözünürlüklü ortofoto görüntüsü

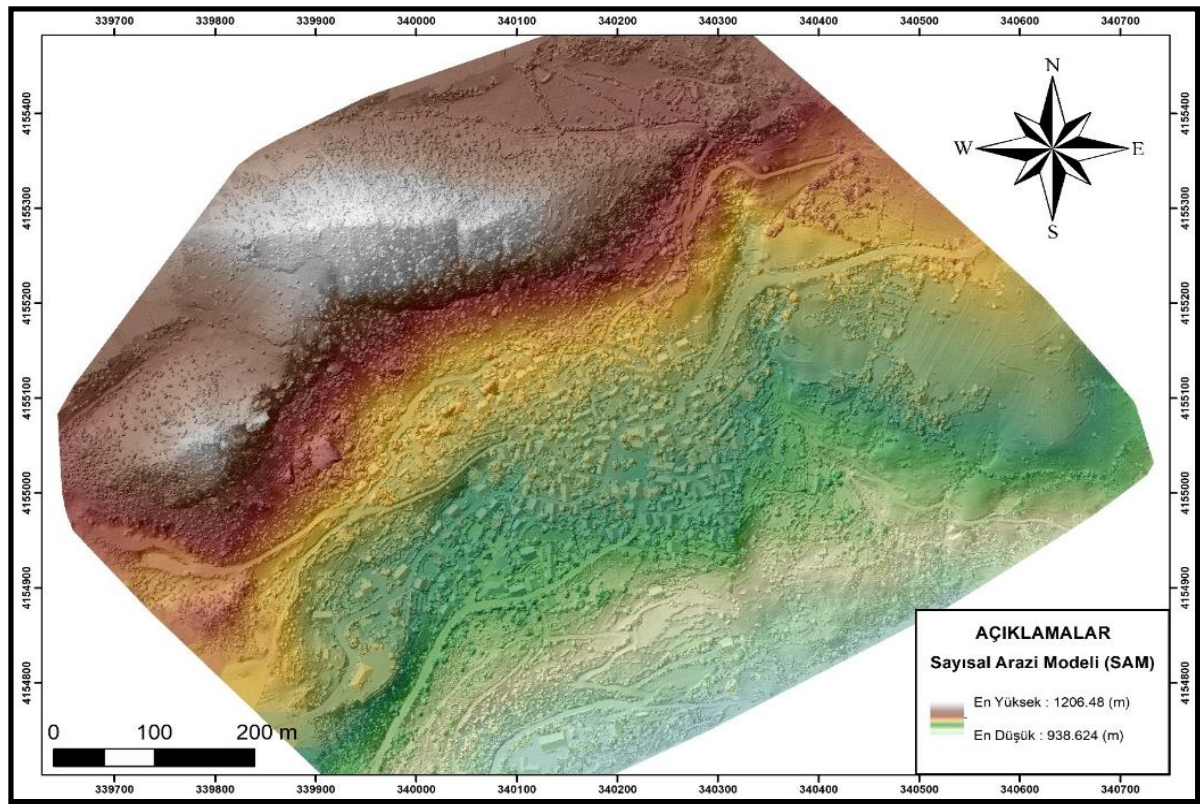

Şekil 6. Çalışma alanının yüksek çözünürlüklü Sayısal Arazi Modeli (SAM)

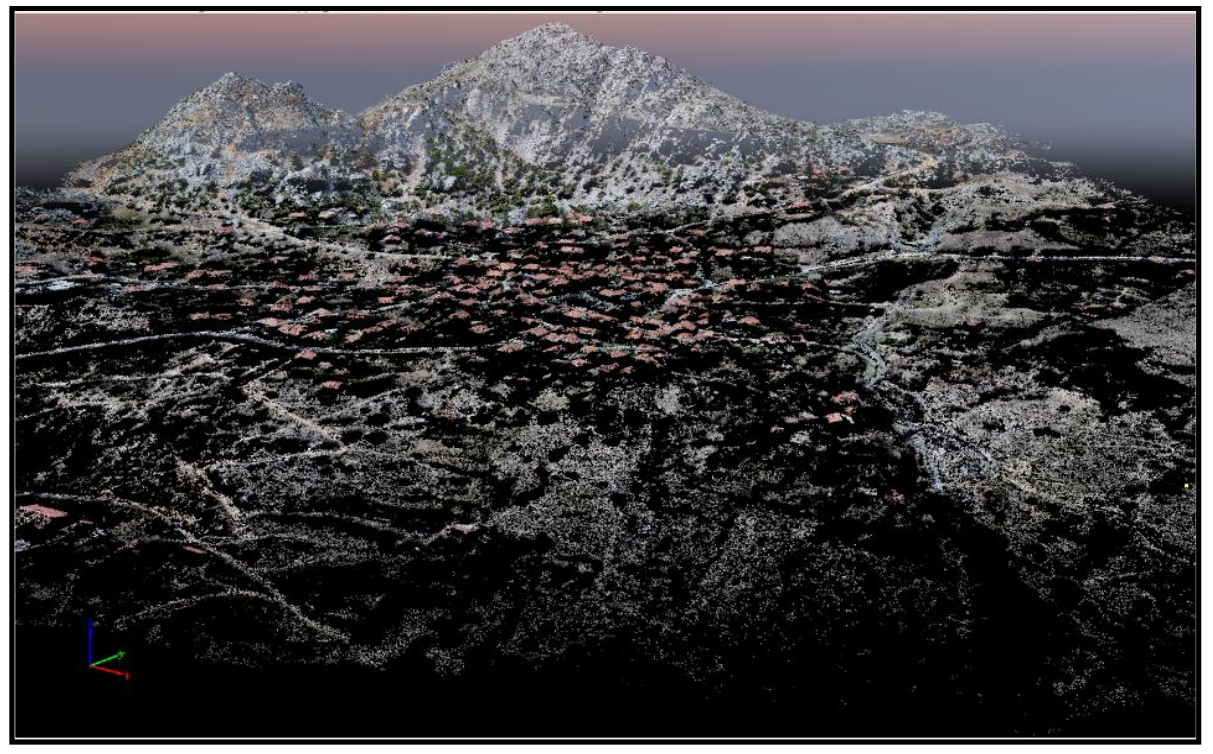

Şekil 7. Çalışma alanına ait nokta bulutu 


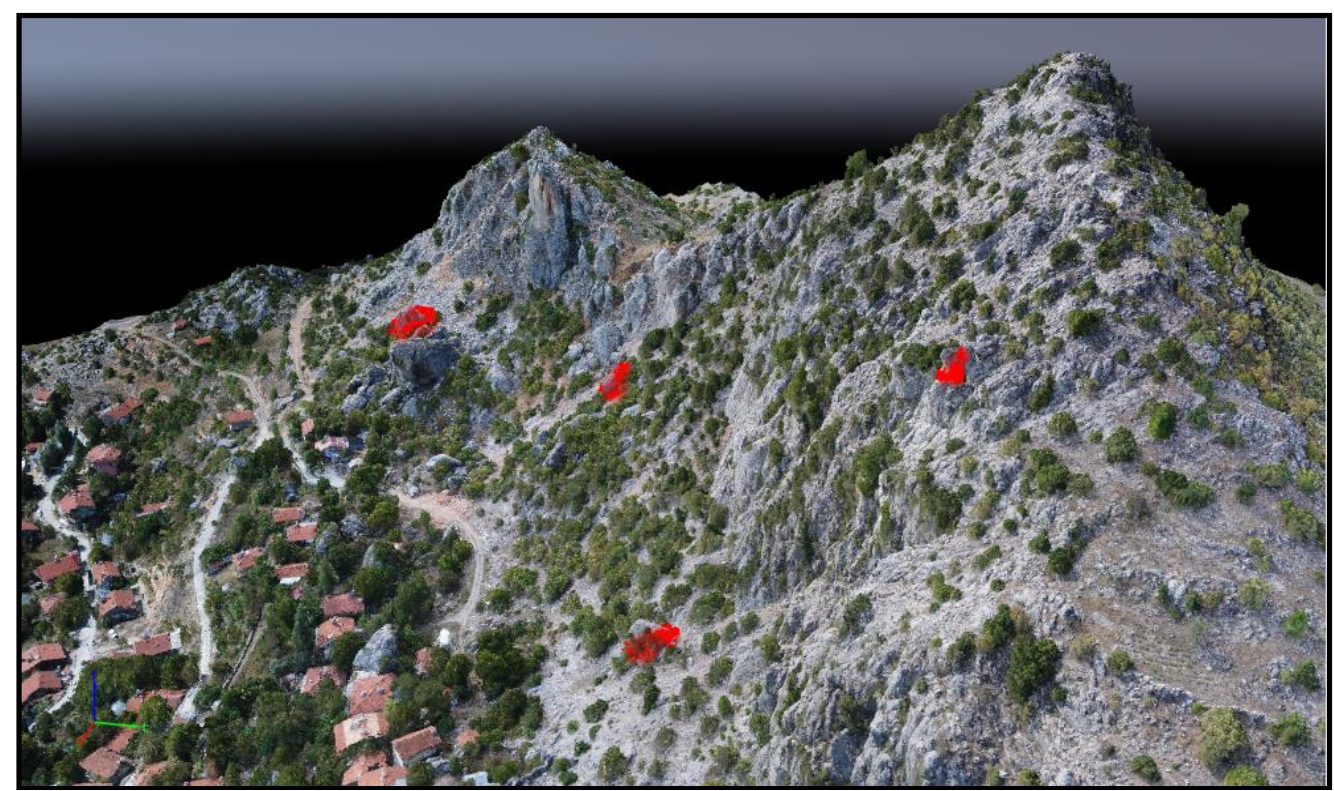

Şekil 8. Çalışma kapsamında modellenen blokların 3D görünümü

Belirlenen herbir bloğun boyutları (yükseklik, genişlik ve uzunluğu) ve hacmi fotogrametrik yöntemlerle belirlendikten sonra blok şekilleri Rockyfor3D yazılımına girdi parametresi olarak kullanılmak üzere uygun formata dönüştürülmüștür. Daha sonra düşme potansiyeli bulunan her bir blok ortamının pürüzlülük yüzde sınıfları (rg10, rg20 ve rg 70) belirlenmiştir. Tüm girdi parametreleri uygun formatta hazırlandıktan sonra Rockyfor3D yazılımı ile 3 boyutlu kaya düşmeleri modellenmiştir.

Rockyfor3D yazılımı daha önceki yıllarda Rocky3, RockyFor olarak adlandırılan yazılım serisinin devamı niteliğinde olup C programlama dilinde yazılmıștır. Analizlerden elde edilen tüm çıktı parametreleri (düşme yörüngeleri, ortalama ve maksimum kinetik enerjiler, sıçrama yükseklikleri vb.) 3 boyutlu haritalandırılmış ve sonuçları grafiklere dökülerek yorumlamalar yapılmıştır (Șekil $9,10,11)$.

Olası kaya düşmelerinin düşme yörüngeleri, sıçrama yükseklikleri ve düşen blokların kinetik enerjilerine ait modelleme çıktıları kullanılarak olası kaya düşmelerinin etkilerinin en aza indirilebilmesi amacıyla bariyer ve hendek tasarımları ile yerinde sabitleme gibi önlemlerden en uygun olanı projelendirilebilir.

\section{Tartışma ve Sonuç}

Çalıșma alanında farklı yaș ve litolojiye sahip stratigrafik birimler yüzeylenmektedir. Bölgede Menteșe Dolomiti, Kasımlar Formasyonu ilet tüm bu birimlerin üzerinde Kuvaterner örtü birimleri olan Alüvyon ve yamaç molozu bulunmakta olup sözkonusu litolojik birimler ayrıntılı olarak haritalandırılmıştır.

Özellikle son yllarda insansız hava araçlarının kullanımlarının yaygınlaşması ile birlikte mühendislik projelerinde kullanımları da artmıștır. Özellikle insansız hava araçları ile üretilen yüksek çözünürlüklü ortofotolar ve nokta bulutları birçok mühendislik projesinde altlık olarak kullanılmaktadır. $\mathrm{Bu}$ çalışmada belirlenen güzergahlarda gerçekleștirilen otonom uçuşlar DJI Matrice 600 Pro model insansız hava aracina entegre edilen Sony A7R fotoğraf makinesi ile 752 adet hava fotoğrafı çekilmiștir. Sözkonusu hava fotoğraflarının fotogrametrik olarak değerlendirilmesi ile çalıșma alanına ait yüksek çözünürlüklü ortofoto ve nokta bulutu üretilmiștir. Süreksizliklerin konumları ile birlikte devamlılıkları, aralıkları ve açıklıkları vb. özellikleri kullanılarak çalışma alanında düşme potansiyeli bulunan 4 adet blok belirlenmiştir. Boyutları $26 \mathrm{~m}^{3}$ ile $355 \mathrm{~m}^{3}$ arasında değişen bu blokların hacimleri fotogrametrik yöntemler ile belirlenmiştir.

Çalışma alanındaki olası kaya düşmelerinin daha hassas modellenebilmesi amacıyla Coğrafi bilgi Sistemleri Tabanlı 3D modelleme yöntemi kullanılmıştır. Sözkonusu modelin kullandığı tüm girdi parametreleri arazi çalışmaları ile fotogrametrik yöntemler kullanılarak elde edilmiştir.

Coğrafi Bilgi Sistemleri ortamında elde edilen tüm girdi parametreleri Rockyfor3D yazılımı ile analiz edilerek çalışma sahasındaki olası kaya düşmeleri 3 boyutlu modellenmiștir.

Çalıșma alanındaki olası kaya düșmelerinin Coğrafi Bilgi Sistemleri tabanlı 3D modelleme sonuçlarına göre olası kaya düşmelerinde maksimum kinetik enerji 55170 kJ, maksimum sıçrama yüksekliği 11.5 $\mathrm{m}$ ve maksimum düşme hızların ise $24.7 \mathrm{~m} / \mathrm{s}$ olduğu belirlenmiştir. Konumsal olarak belirlenen bu veriler kullanılarak olası kaya düșmelerini engellemeye veya etkilerinin en aza indirilmesine yönelik yapılacak mühendislik yapıları projelendirilebilir. 


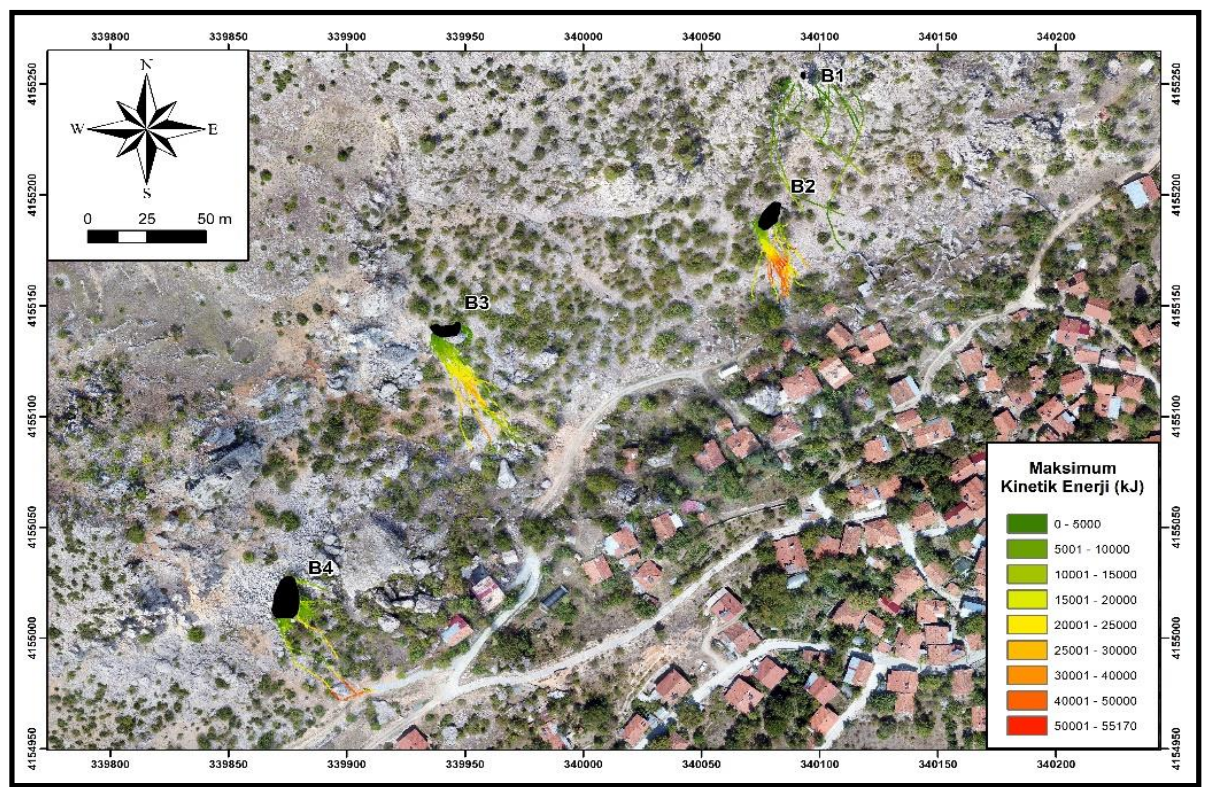

Şekil 9. Çalışma alanındaki blokların maksimum kinetik enerjileri

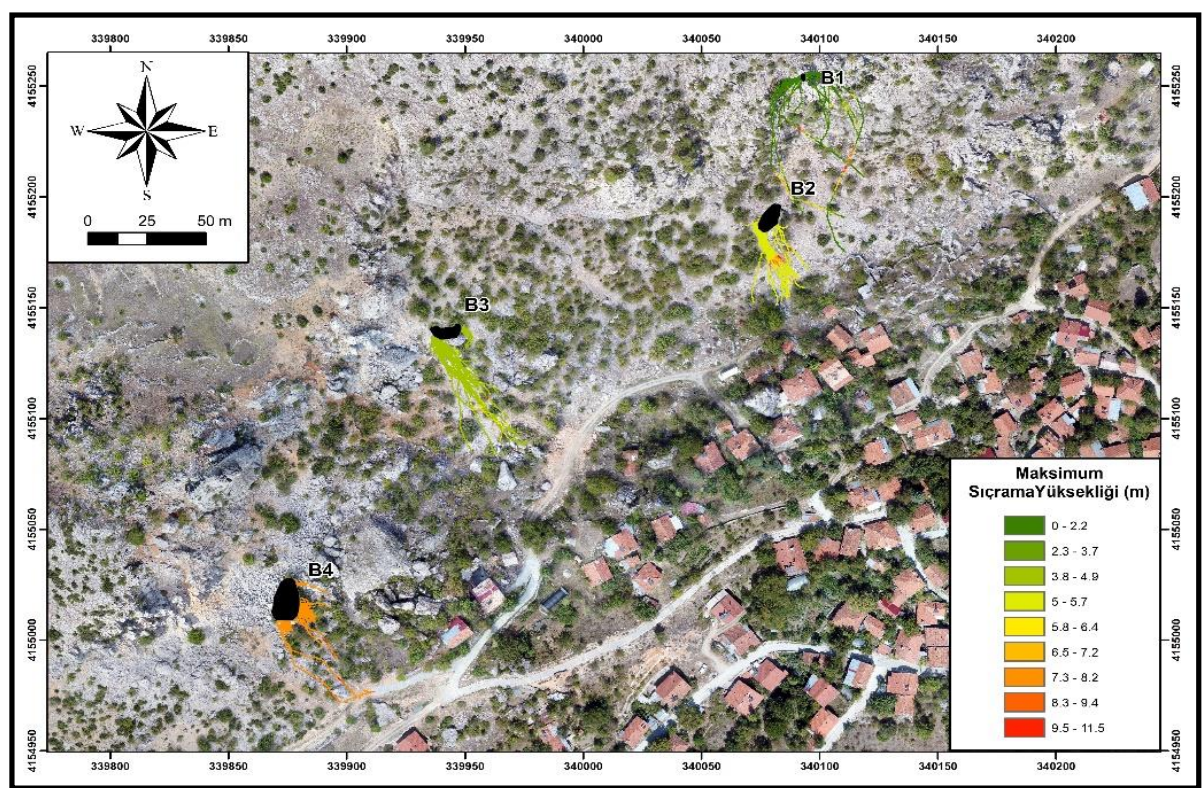

Şekil 10. Çalışma alanındaki blokların maksimum sıçrama yükseklikleri

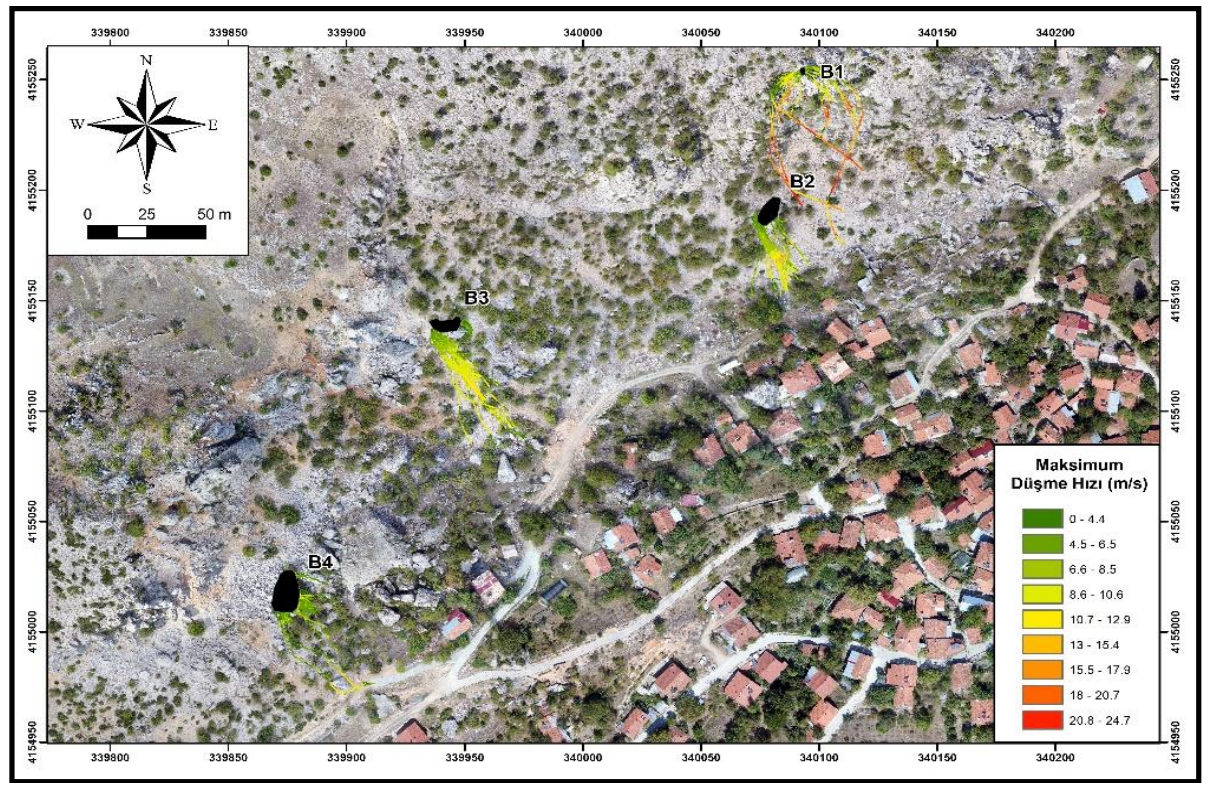

Şekil 11. Çalışma alanındaki blokların maksimum düşme hızları $(\mathrm{m} / \mathrm{s})$ 


\section{Teşekkür}

$\mathrm{Bu}$ çalışmayı finansal olarak destekleyen Isparta İl Afet ve Acil Müdürlüğü' ile arazi çalışmalarındaki desteklerinden dolayı Isparta İ Afet ve Acil Müdürlüğü' teknik personeline teşekkürlerimi sunarım.

\section{Kaynaklar}

[1] Varnes, D.J., 1978. Slope movements: types and processes. In: Schuster, R.L., Krizek, R.J.(Eds.), Landslide Analysis and Control. Transportation Research Board, Special Report No. 176, Washington, DC, 11-33.

[2] Hutchinson, J. N., 1988. Morphological and geotechnical parameters of landslide in relation to geology and hydrogeology, 5th international symposium on landslides, 10 - 15 July, Lausanne, 1, 3-35.

[3] Cruden, D.M., Varnes, D.J., 1996. Landslide Types and Processes. Landslides Investigation and Mitigation, Special Report 247, 36-75.

[4] AFAD., 2015. Bütünleşik Afet Tehlike Harita Hazırlanması: Heyelan-Kaya Düşmesi Temel Kılavuzu, Planlama ve Zarar Azaltma Dairesi Başkanlığı, 152s, Ankara

[5] Whalley, W. B. 1984. Rockfalls, in: Slope Instability, Wiley, Chichester, 217-256.

[6] Perret, S., F. Dolf, H. Kienholz, 2004. Rockfalls into forests: analysis and simulation of rockfall trajectories - considerations with respect to mountainous forests in Switzerland. Landslides. 1, 123-130.

[7] Hungr, O., Evans, S. G., Hazzard, J. 1999. Magnitude and frequency of rock falls and rock slides along the main transportation corridors on southwestern British Columbia. Canadian Geotechnical Journal, 36, 224-238.

[8] Peckover, F. L. 1975. Treatment of rock falls on railway lines. American Railway Engineering Association, Bulletin 653, 471-503.

[9] Chau, K. T., Wong, R. H. C., Liu, J., Lee, C. F. 2003. Rockfall hazard analysis for Hong Kong based on rockfall inventory. Rock Mechanics and Rock Engineering, 36(5), 383-408.

[10] Gökçe, O., Özden, Ş., Demir, A. 2008. Türkiye'de afetlerin mekansal ve istatistiksel dağllımı afet bilgileri envanteri. Bayındırlık ve İskan Bakanlığı Afet İşleri Genel Müdürlüğü, 126 s, Ankara.
[11] Guzzetti, F., Crosta, G., Detti, R., Agliardi, F. 2002. STONE: a computer program for the threedimensional simulation of rock-falls, Computers \& Geosciences, 28, 1079-1093.

[12] Dorren, L. K. A. 2003. A review of rockfall mechanics and modelling approaches, Progress in Physical Geography, 27, 69-87.

[13] Liniger, M. 2000. Computer simulation von Stein- und Blockschl"agen, Felsbau, 18, 64-68.

[14] Le Hir, C., Berger, F., Dorren, L. K. A.,, Qu'etel, C. 2004. Forest: a natural means of protection against rockfall, but how to reach sustainable mitigation? Advantages and limitations of combining rockfall models taking the forest into account, International Congress Interpraevent, 23-28 May, Riva del Garda, Italy, 2, 59-69.

[15] Dorren, L. K. A., Maier, B., Putters, U. S.,, Seijmonsbergen, A.C. 2004. Combining field and modelling techniques to assess rockfall dynamics on a protection forest hillslope in the European Alps, Geomorphology, 57, 151-167.

[16] Dorren L.K.A. 2016. Rockyfor3D (v5.2) revealed - Transparent description of the complete 3D rockfall model. ecorisQ paper (www.ecorisq.org): $32 \mathrm{p}$.

[17] Dorren, L.K.A., Berger, F., Putters, U.S., 2006. Real-size experiments and 3-D simulation of rockfall on forested and non-forested slopes. Natural Hazards and Earth System Sciences, 6(1), pp.145-153.

[18] Dumont, J.F., Kerey, E., 1975. Eğirdir Gölü güneyinin (Isparta ili) temel jeolojik etüdü. Türkiye Jeoloji Kurultayı Bülteni, 18 (2), 1-10.

[19] Bozcu, A. 2007. Zindan Mağarası ve Çevresinin Jeolojik - Arkeolojik Özellikleri. Süleyman Demirel Üniversitesi Fen Bilimleri Enstitüsü Dergisi, 11(1), 54-63.

[20] Şenel, M., Dalkılıç, H.; Gedik, l.; Serdaroğlu, M.; Bölükbaşı, A.S.; Metin, S.; Esentürk, K.; Bilgin, A.Z.; Uğuz, M.F.; Korucu, M., Özgül, N. 1992. Eğirdir-Yenişarbademli- Gebiz ve Geriş- Köprülü (Isparta- Antalya) arasında kalan alanların jeolojisi. MTA Rapor No: 9390, TPAO Rapor No: 3132 (yayımlanmamış), 559s, Ankara.

[21] Şenel, M., Gedik, haz, Dalkılıç, H., Serdaroğlu, M., Bilgin A.Z., Uğuz, M.F. Bölükbaşı, A.S., Metin, Y., Korucu, M., Özgül, N. 1996. Isparta Büklümü Doğusunda, Otokton ve Allokton Birimlerin Stratigrafisi (Batı Toroslar). Maden Tetkik Arama Dergisi, 118, 111-160. 